\title{
Report of the Panel on Epidemiology and Control
}

Chairman: M. F. Lechat; Secretary: B. I). Molesworth; Members: E. Agricola; D. A. Akintonde ; L. M. Baliña; L. M. Bechelli; C. M. Brusco; W. M. Cantidio; O. Diniz, E. H. Hermans; C. Kettanurak; J. A. Madeira; M. Orusco; F. E. Rabello; A. Salazar Leite; H. Sansarricq; A. Saúl. Two members were invited but were unable to attend: Drs. D. L. Leiker and C. M. Ross. Drs. J. M. de Barros and R. Huerta attended the meetings of the Panel as observers.

\section{E P I D E M I O L O G Y}

Epidemiology of leprosy deals more particularly with relationship between the incidence of leprosy or its various forms and determinants such as host factors or ecologic conditions which may affect either exposure to infection or resistance to the disease. By so doing, it is possible to develop and test sound measures for its control. It implies definitions, measurements, and research. 


\section{DEFINITIONS}

Comparisons between frequencies of the morbid characteristic under investigation in different situations is one of the basic tools of epidemiology. It is therefore of the utmost importance that terminology, screening methods and procedures of diagnosis be clearly defined. It is particularly so for leprosy, because of the variations in the manifestations and evolution of the disease in different populations.

With regard to the screening of populations, records should indicate on which diagnostic criteria the epidemiological indices are based. It is a fact that in various parts of the world, and even in adjacent countries, leprologists give slightly different interpretations to the definition of the types of leprosy. In order to take into account these variations for epidemiological studies, methods should be clearly stated.

The personnel should use standard strategies in each area. In global reports, pooling of data reported by various types of personnel using different procedures should be avoided, or at least the methods indicated.

For correlation of findings on a world basis, terminology, methods and technics used for epidemiological study of leprosy should be uniform. Co-operation of wHO is sought in this respect.

\section{MEASUREMENTS}

(a) Prevalence. The importance of obtaining reliable estimates of prevalence of leprosy cannot be exaggerated. Only in this way can an adequate basis be provided for planning and implementing the antileprosy campaign and evaluating its results. Furthermore the Congress emphasizes the importance of prevalence in specific groups of the population.

In practice, due to the long time required for surveying a large population, prevalence rates as expressed in leprosy are period prevalence rates.

Duc care should be exercised to distinguish adequately registered and discharged cases.

There are different surveying methods to secure prevalence data. Prior to describing these, it must be stressed that the final purpose of a leprosy survey is positively the control of the disease and its treatment, and not merely the collection of data. Therefore, it is emphasized that any type of survey must always and at once be followed by treatment.

Health education is essential to ensure the success of surveys.

(i) Total population surveys. The best measure of prevalence is obtained by a survey covering the whole population of the area under consideration. Such a method, however, is justified only if from previous experience it is known that the prevalance is high. Total population surveys for leprosy may sometimes be usefully combined with other mass operations, such as smallpox vaccination, yaws mass treatment, etc. It is generally better to concentrate systematically the efforts first on one selected area, and therefore to start by a pilot project which will later on be extended progressively to the whole country, taking advantage of the experience gained in the first location. 
Whatever the efforts made to cover the whole population of an area, it is highly unlikely that roo per cent of the individuals will be examined. Serious consideration must be given to the individuals who do not show up, because an association between non-response and the disease may introduce a considerable bias in the results of the survey. For example, non-response may be due to fear of the disease being discovered. There-

an assessment of the magnitude and of the causes of non-response must be made. Special attention should be given to the allocation of patients hospitalized in leprosaria with regard to their place of origin. Total population surveys require an adequate census of the population.

(ii) Sampling survey. Often, however, total population surveys are not feasible. Physical examination of the whole population may be beyond the available resources in terms of budget or personnel. In some cases no previous estimate of the prevalence is available or demographic data are insufficient. In many countries, due to psychological or sociological reasons, such as systematic refusal of health measures, nomadism, physical examination of the whole population is not possible. In these cases, estimates must be made in other ways. The best method is a sampling survey. The sample can be constituted by individuals, by households or by villages randomly selected.

These questions demand, in every instance, joint planning by leprologists, cpidemiologists and statisticians, in liaison with civil administrative officials, community leaders and persons experienced with the situation in the area.

If such surveys are feasible, their cost will be repaid many times by a sound planning of the campaign leading to a greater efficiency of the leprosy control.

(iii) Selective survey. When sampling surveys are not feasible, nonsystematic operations dealing with villages or other population units may be useful for case-finding. Extreme caution must, however, be exercised to interpret their results because choice of the population surveyed as well as responsiveness of the individuals may be associated with the presence or absence of leprosy. In these cases, prevalence data are difficult to derive.

A most efficient method to detect new cases may be, instead of a survey, the systematic search for and supervision of contacts. This is especially useful when prevalence is low. What is understood by contact must then be clearly defined. In this case, the same caution must be exercised with respect to the derivation of epidemiological indices.

Surveys in selected groups, such as schoolchildren, may yield very useful information, but caution must be exercised not to extrapolate these results to the entire population.

It cannot be too strongly emphasized that in any case, when recording prevalence data, detailed explanation must be given as to the manner by which these data have been collected; by total survey, sample survey, selective survey, examination of contacts, spontaneous attendance, compilation of files, examination of inmates of leprosaria, or unsystematic 
search. The denominator, i.e., the population examined, must be accurately defined. A high proportion of children among the patients means one thing if the whole population has been examined, and quite another if, for reasons of easy accessibility, schools have been preferentially surveyed. No valid comparison, sound planning, or forecast for the future can be made unless due consideration is given to these matters. Description of the procedures employed to estimate prevalence is no less important than the figures reported.

Prevalence applies also to various characteristics of the disease. 'The prevalence of lepromatous leprosy in a population is expressed by number of lepromatous cases

$$
\text { X IOOO }
$$

at a given time.

total population

If active lepromatous patients only are under consideration, to the exclusion of negative cases who are discharged or residual, the prevalence of bacterioligically positive cases is a valuable rate.

The prevalence of deformities among leprosy patients is a useful measurement to assess the needs for rehabilitation, reconstructive surgery and social help. It has scldom been determined, and data are urgently needed in this respect. Care must be taken to base this rate on the examination of a representative group of patients, and not only on patients hospitalized in institutions.

(b) Incidence. 'This refers to the number of events occurring during a period of time.

The incidence of leprosy is expressed as new cases over a given interval of time

total population at the beginning of the time interval

$\mathrm{X} \mathrm{IOOO}$

It is a very useful concept, for it gives information on the trend, progression or regression, of the disease.

This rate does not necessarily refer to the whole population, and may apply to a specific group. If so, it must be clearly stated.

Incidence data for leprosy are few and difficult to derive. They may be obtained by two methods. One is to follow the population during a given time and to register the number of new cases. Another is to repeat prevalence surveys after an interval of time and compare the results with previous surveys, making provision for patients deceased or lost to observation during the interval. In places where leprosy activities are well developed, with early detection, the number of new cases registered gives a fair approximation of the incidence. In most of the situations, however, the number of new cases detected does not correspond to incidence, because a considerable lapse of time often occurs between the onset of the disease and its detection.

Incidence may apply to other characteristics of the disease, such as bacteriologically positive cases, deformities in treated or non-treated patients, lepra reaction or relapses. These rates are useful for the planning and allocation of specialized medical facilities. 
(c) Ratio lepromatous/total number of patients. 'I his ratio is expressed as number of cases of lepromatous leprosy

$$
\text { X I00 }
$$

total number of leprosy patients

It can be misleading, because experience has shown that during a mass campaign the rate of discovery is not the same for the different types of leprosy, under various conditions. 'This ratio should therefore always be followed by the prevalence figure for lepromatous leprosy as indicated above.

(d) ()ther measurements. Some other measurements may be useful for a better knowledge of the epidemiology of leprosy. Such are the distribution of ages at onset, the duration between onset and detection, and the attack rates among contacts. The proportion of indeterminate cases among the newly detected leprosy patients is also a useful index to assess the completeness of the detection and the earliness of diagnosis in a case-finding campaign.

(c) Measurements needing researches. Very little is known about the effect of leprosy, or of each type of leprosy on survival. Lifc-tables for leprosy patients, with life expectancy for each age of onset, should be devcloped.

\section{RESEARCII}

Epidemiological research in leprosy is considerably hampered by our present lack of fundamental knowledge.

'The fact that $M$. leprae has not yet been cultivated nor routincly transmitted to animals has prevented any experimental study of the agent factors involved in the spread of the disease. Host-factors are difficult to investigate due to the absence of bacteriologic, serologic or skin-test methods for detecting latent or possibly non-apparent infections. The length of the silent period before clinical onset makes it often impossible to single out simple environmental factors.

In these conditions, the prospects for epidemiological investigations in leprosy are heavily dependent upon achievements in the corresponding ficlds of microbiology and immunology. It is anticipated that extension and speeding-up of research in these fields will provide the epidemiologist with new baselines and new tools.

In the present state of knowledge, certain special problems should be studied:

(I) GENETICs. Several observations suggest a possible role of genetic factors in the susceptibility or resistance of individuals and populations to leprosy or to the lepromatous type of the discase.

'The possibility of a genetic mechanism should be studied with respect:

(a) to leprosy itself; (b) to the polar types of the disease; (c) to the occurrence of lepra reaction in lepromatous leprosy; (d) to reactivity to tuberculin associated with non-reactivity to lepromin; (e) to the nonversion of the lepromin-reaction after BCG. 
'These problems could be studied in twins, in families, and in populations. In each case, they will require a joint planning by a statistician, an epidemiologist, a geneticist and a leprologist, for they call for highly claborate mothods of sampling and statistical interpretation.

For twins' study, a world central registrar of twins with leprosy should be set up, eventually with the help of who.

Studies of familial aggregation should be undertaken or expanded in areas where good demographic and clinical records have been available for several gencrations.

Methods of population genetics should be applied to leprosy. Studies of genetic polymorphisms associated with leprosy and with its manifestations should be expanded and co-ordinated, in order to procece in various parts of the world among patients and controls to a large screcning of the genetic markers known at present. The development of micro-methods for field use, shipment or storage has radically modified and colarged the scope of possible investigations, and should be largely used in leprosy. (o)-operation with serum banks should be sought, and blood samples collected and deposited for further investigations as new methods will be made available and new genetic markers discovered.

(2) I.ePromin-kEacition. Studies on the relationship between leprominreactivity and other lactors in populations have yielded valuable information. 'These studies should be continued, expanded and repeated.

Among the problems which deserve special interest are:

(a) The relationship) between lepromin-reactivity and skin-reactivity to other antigens.

(b) 'The relationship) between lepromin-reactivity in healthy persons and the further incidence of leprosy among them, with special reference to the type of leprosy they eventually develop.

(c) The incidence of leprosy, especially of lepromatous leprosy, among people having received $B C G$, in relationship with the effect of $B C G$ on the conversion of their Mitsuda test.

(d) Determination of the proportion of poor reactors to lepromin under natural conditions.

Such studies are extremely difficult from a statistical point of view. Sampling has many pitfalls. Hence, the controversial aspects of the results.

Another difficulty comes from the lack of standardized antigen for skin-testing in leprosy, and from different criteria for the reading of the test, often making impossible the comparison or reproduction of the results.

(3) ATtTAG RATES AMONG household contacis. Attack rates among household contacts should be studied and compared in different parts of the world, wherever reliable data are available, keeping as a model of such investigation the studies of Doull and coll. in the Philippines. Iifetable methods may be used, or other epidemiological methods could cventually be designed after consultation with mathematicians. 
Special attention should be given to attack rates among contacts with respect to the type of leprosy in the index case. A point of particular importance is the role of tuberculoid cases in the transmission of the disease in areas of the world where open cases constitute only a small proportion of the cases.

(4) urbanization. In some countries highly prevalent with leprosy, recent industrialization has resulted in a shift from a purcly rural population to a partly urban population, often overcrowded and of a low economic level. 'That is, for example, the case in several cities of Africa and in South-cast Asia. In order to provide baselines for subsequent studies of the environmental factors, it is recommended that data would be collected and assembled on the incidence of leprosy in these urban populations. 'This population being generally constituted of workers, henee selected, special attention should be given to avoid bias in sampling.

(5) I.Imited foc:I. Islands, ethnic minoritics, displaced populations, isolated communities often offer peculiar patterns in the distribution of the discase. Inventory of these limited foci should be made, and their epidemiological study encouraged and given the necessary help.

(6) FIRST Lesions. High frequencies of occurrence of the first lesions of leprosy at certain specific sites of the body, especially for tuberculoid leprosy, have been recorded. Differences in these sites are reported according to various countries and behaviour patterns. Further studies on this questions would be valuable, in order to bring light on the mechanism of transmission of leprosy and the portal of entry of the micro-organism.

(7) ARTHROPOD-VECTORS. 'The possible role of insects in the transmission of leprosy has been neglected for long. More data is needed relating to the cultivability of acid-fast bacilli found in various insects, and on the relative frequency of such findings in insects found in association with cases of leprosy as compared to these found in other places.

(8) CARrier stage. Observations have been reported of acid-fast bacilli found by special concentration techniques in the skin of a high percentage of apparently healthy contacts of leprosy patients. If these observations are confirmed, this leads to the concept of a carrier stage in leprosy.

Due to the great importance of this question, it is suggested that this type of study be repcated on a large scale by different investigators.

(9) SPONTANEOUS HeALing. It has been reported that a large proportion of the children developing leprosy heal spontaneously. More information is nceded on the diagnostic criteria available to recognize early lesions, on the frequency of spontaneous healing in adults, and on the immunological and possibly genetic factors associated with this favourable type of evolution. 
(io) ASSOciation OF DISEASF. Iittle is known about the association between leprosy and other pathological conditions. Data should be collected on the respective incidence of other diseases, especially transmissible ones, among these tuberculosis, in persons with leprosy, in order to disentangle possible immunological relationships.

In the same line, cause-specific mortality rates should be collected in leprosy patients.

(I 1) DEFORMITIEs. 'I'he problem of deformities in leprosy has been almost completely neglected until recently. It is well recognized today that it is probably one of the most important problems the leprologists have to deal with. 'Therefore, it secms timcly to start collecting cpidemiological data in this regard.

Epidemiological methods should be widely used for the study of deformities: prevalence and incidence rates, broken down by age, sex and type of leprosy, etc.; average delay before onset; rapidity of development; association with various factors such as previous occupation, ethnic group, occurrence of lepra reaction, etc. 'This could throw some light on the etiology of the various types of deformities cncountered in leprosy.

(i2) Lepra rfaction. Fpidemiological methods should be more extensively applicd to the study of lepra reaction.

(13) NUTrition. Ntrition requires detailed studies by nutritional workers in areas of high endemicity which may produce findings not obvious to casual untrained observers.

(I4) misciellaneous. 'The various factors which may influence the epidemiology of leprosy are so many that here only a brief list is given for which data could be available or obtained.

(a) Prevalence and type of leprosy in relation to race, climate, altitude or living conditions.

(b) Information regarding relapses after treatment.

(c) Possible role of tuberculoid cases in the transmission of lepro ys.

(d) Influence of puberty, pregnancy, scvere illness, change of conditions or menopause on the development of leprosy.

(c) Modification in the epidemiology resulting from changes in control policies such as the replacement of compulsory segregation by outpatient treatment.

\section{(:ONTROL}

Due to its long duration and to the deformities it causes, leprosy constitutes a severe burden for the affected individual as well as for the community. In many countries, it is only one of the major health problems, consequently it must be dealt with in co-ordination with other public health programmes. Among these programmes, however, it deserves a high priority.

Control of leprosy has for objective the progressive reduction of its morbidity, in such a manner that it no longer constitutes a public healt h 
problem. Its far-reaching goal is the cradication of the disease. It implies activities following three lines: prevention, carly detection, and treatment. Rehabilitation is the necessary complement.

Measures to meet these objectives may be grouped under six headlings: (i) administrative; (ii) medical; (iii) training of personnel; (iv) health education; (v) social; (vi) legal. Research to improve and to continuously adapt these measures are needed.

One must however, realise that in many circumstances there is a gap between what should be done and what can be done. Iceprosy control is inseparable from the development of other health activities and of the potential of the whole nation. Difficulties may also be encountered as a result of previous leprosy campaigns, leading to the necessary acceptance of facilities, personnel and even methods which are not in accordance with present conditions or new concepts. In such cases, it is sometimes necessary to cope with the situation as it stands, making the best possible use of it and modifying it progressively, rather than to seck drastic changes.

( 1 Administrative measures. Action must be in agrecment with general principles of public health. Therefore it must include planning, programming, organisation and evaluation. I.cprosy control programmes, as any public health programme, should have quantitative objectives and the various factors that define them should be weighed.

In countries where leprosy is considered as a problem of public health, there should be a service in charge of it, attached to the higher administrative level in charge of health. The Chief of the Scrvice should have adequate training in leprosy and in public health administration.

Technical advice and the establishment of standards at central level as followed by administrative and executive decentralisation are the principles on which the structure of leprosy control should be based.

Gradual integration of the leprosy campaign into the general health services is highly desirable. Although such an integration may have to be delayed until those services are sufficiently developed as to make this integration possible, it should be started as soon as possible.

(2) MEdical measures. The principal weapon of the anti-leprosy campaign is still chemotherapy with sulfone drugs. Regular and prolonged sulfone treatment, gencrally over several years, reduces infectiousness in the majority of cases. It follows that if a considerable proportion of bacteriologically positive patients are treated, the disease will decline. Sulfones, however, do not arrest the progress of deformities once these are initiated, and appropriate action must be taken to prevent and correct deformities.

For special cases, or in particular situations, other chemotherapcutic. drugs are valuable.

Other means, either of a preventive nature, or of a therapeutic nature such as a rapidly effective bactericidal drug, are urgently needed. If these should become available, it would likcly change our present approach and lead to a modification of the measures outlined in this report. 
At present, therefore, in many countries, and as a result of the large number of patients and limited resources, control implies mass treatment by a form of sulfone therapy which can be administered safely and with standard methods by auxiliary workers supervised by highly qualified medical personnel. DDS administered either by mouth or by repository injections fulfills these requirements. The primary problem, thus, becomes largely a logistic one: to make the optimal use of medical facilities, budget and personnel in order to detect and to treat a maximum number of patients, especially those who are bacteriologically positive or likely to become positive, to detect and to treat patients early enough in the course of the disease, to apply therapy when it is most effective, to prevent the onset of deformities, and to secure regular attendance of the patients to a treatment prolonged over several years.

Medical measures therefore are threefold: (i) case finding; (ii) treatment; (iii) protection of healthy population with special reference to contacts.

Measures must be adapted to the region under consideration. To do this, the importance of a preliminary survey is stressed. The leprosy campaign should start first by a pilot project in a selected area. This pilot project should serve to adapt general principles of leprosy control to the local situation, in prospect to future development, as well as to train personnel. Expansion of the work to other areas should be progressive and systematic, in keeping with the development of the local health services.

Control measures must be continuously corrected and adapted as the campaign progresses and more experience is gained. Efficient control, therefore, implies evaluation of the results. Built-in methods of cvaluating the results are mainly a matter of local conditions, and their use cannot be generalised at present. As a matter of principle, however, one should seek simplicity and avoid undue multiplications of forms and reports, whose only result is to harass the worker in the field and to yicld loose information. A few accurate facts are better than a large number of inaccurate ones.

It is obvious that co-operation of any available adequate resources, in terms of medical facilities or manpower, governmental or voluntary, will be sought, following the lines laid down by the leprosy service.

(a) Case finding. Procedure for detecting cases of leprosy has been described in the first part of this report, dealing with prevalence estimates.

Depending on the estimated prevalence in the area, detection may be obtained by different methods.

In areas where prevalence is high, detection should be performed by periodic examination of the whole population because all the individuals have to be considered as possible contacts. Annual intervals, wherever possible, are recommended for these examinations.

In areas with low prevalence, detection should be based on periodic examination of contacts of known cases, and also on screening selected groups such as school children, job-seeking individuals, workers, etc. 
Contacts exposed for many years who show no manifestation of the discase need only an occasional supervision.

In areas where the prevalence is between these two extremes, detection could be obtained by resorting to either of the methods above mentioned.

'These surveys need not be for leprosy only, and it may be advantageous to perform multipurpose operations.

Methods of screening and criteria of diagnosis should be precisely defined. 'l'hey should be adapted to conditions prevailing in each country, taking account of the skill of the personnel.

(b) IVavs of treatmenl. In any and all cases, detection must be followed by treatment, either by the surveying team, or through referral to a leprosy treatment unit. If a multistep procedure is used for detection, with preliminary screening by auxiliary workers, treatment should not be withheld pending confirmation of the diagnosis. Emphasis should be placed on the necessity of early, regular and prolonged treatment. 'The possibility of reactions and other complications should be anticipated.

Methods will be different with regard to out-patients and in-patients.

(i) Out-patient care. Depending on the stage of development of the local health scrvices, out-patient care should be carried on by fixed health centres, by mobile units, or both.

'There should be an adequate number of such facilities, the number and distribution being related to the prevalence of the disease in various regions. 'Ireatment centres should be conveniently accessible and so located as to serve the largest number of patients.

Fixed centres that are staffed and equipped for general public health scrvices, such as health centres, rural polyclinics, and dispensaries, should be progressively adapted to carry out all functions essential to the antileprosy programme, integrating them in their basic activities of preventive and curative medicine. These leprosy functions include at least the recognition, treatment and follow-up of patients. Whenever and wherever possible they should extend to include examination of contacts, application of simple techniques of rehabilitation, surveys for leprosy in the local population, home nursing and social work.

In countries where dermatological clinics are well developed, these may collaborate to perform leprosy activities.

Wherever necessary, fixed centres should be supplemented by mobile units. Advantage should be taken of these mobile teams to launch other health activities in such a manner that it will constitute a nucleus for developing integrated services later on.

The best method to avoid disability is to prevent it. In both fixed centres and mobile units the need to prevent deformities should be stressed. Simple techniques for reaching this aim can in fact be performed by any member of the staff who has received the necessary instructions and this should be done in each centre and even in the field. Even for rehabilitation, it is desirable that it takes place in the environment in which the patient lives. Special rehabilitation centres should be con- 
sidered only in countries where the control of the discase has reached a satisfactory level.

Special caution is advised because treatment may induce acute complications and these may result in turn in permanent damage for the patients, unmanageable situations for the para-medical workers and loss of confidence for treatment in other patients.

'The major problem raised by the out-patient treatment is the poor attendance. In some countries this is especially noted in children. Because of the long duration of therapy many of the patients do not pursue treatment to completion. It must not be concealed that duc to irregular treatment our present methods of control are in danger of failure.

Since many methods have been used for the administration of treatment : repository injections or distribution of tablets either for immediate intake or in the form of supply, the best means must be found and adapted (o) local conditions.

Punctuality in the schedules, health education, careful and comprehensive follow-up, care for disabilities and treatment of minor ailments, are essential to improve the attendance. An undue multiplication of the treatment centres is not necessarily efficient, since a point of diminishing return is reached where the neglectfulness of the patient becomes more important as a factor of non-attendance than the difficulty of access to the clinic. Regular inspection by the medical officer in charge, including examination of the patients and discharge of those for whom it is justified, is of prime importance. Patients cannot be expected to attend treatment regularly if they feel that no assessment of their condition is made.

Rescarch is needed with respect to finding the causes of poor attendance and the measures to remedy it in various areas.

(ii) In-patient care. Indiscriminate and compulsory isolation for leprosy is condemned.

(a) Up-to-date facilities for in-patient care, however, are necessary for those in acute reactional phenomena, resistant to routine treatment, intolerant to drugs, or requiring reconstructive surgery and other rehabilitation measures. Construction of such small units may be advisable. These facilities should be located near, tied in or better integrated into a general hospital, in order to benefit from the services of various specialities.

(b) In countries with already existing adequate facilities, the most infectious cases could be induced to enter sanatoria on a voluntary basis. The period of hospitalization should be temporary, and only sufficient to effect clinical regression and to reduce infectiousness. A prolonged series of negative smears should not be required for discharge. A rapid turnover of the patients in sanatoria, with early transfer to out-patient treatment, will reduce the chance of social atrophy due to institutionalization.

Due consideration should be given to the care of burnt-out cases, indigent and irremediable invalids. Care should be taken, however, that this category of patients, and even more that reluctant negatives, do not jam the existing facilities.

These sanatoria form also the centres for research, for training of 
professional personnel of all grades and for special surgery. A large part of the activities must be directed to rehabilitation.

l.eprosaria should be adapted to perform these functions. The construction of new large institutions is positively not recommended.

Hospital facilities should co-exist with out-patient treatment and they should be complementary, but efforts at hospitalization should not be permitted to drain the budget and the efficiency of out-patient treatment centres, which form the core of leprosy control.

(c) A special type of set-up, in various parts of the world, is the segregation village, or agricultural colony, where patients assemble more or less spontaneously. These villages may be made up of infectious patients excluded from the community for social or cultural reasons, by outpatients from far away who assemble in the vicinity of an out-patient clinic, by burnt-out cases, or by patients discharged from a leprosarium who are unwilling or unprepared to reintegrate in their community. In many cases, the existence of these villages results from historical or cultural patterns, or points to some deficiency in the system, which will be corrected as the campaign develops. Therefore, it is recommended that the causes of these deficiencies be found and corrected. If these cannot readily be corrected, it is better to cope with the situation and to make the best possible use of these villages.

Villages for crippled patients who cannot be helped by restorative measures may be useful, if medical, social and psychological care are provided. Welfare services and voluntary agencies can be of great use in taking care of these patients.

Villages of discharged patients point to a lack of social rehabilitation and vocational training in the institutions and serious effort has to be made to prevent such a situation.

(c) Protection of the healthy population with special reference to contacts and children

(i) Removal of children. In many countries experience has shown that to remove an infant from its mother increases the mortality. 'The separation of a baby from its lepromatous parents is therefore not generally recommended and leprosy must be taken as a calculated risk and other methods of protection attempted.

$\Lambda$ temporary separation, however, can be considered where adequate crèche facilities or willing relatives exist, until such time as the parent is negative. Psychological trauma is so important that the period should be reduced to the minimum.

There is no need of special institutions for children of leprous parents but, when institutional care is necessary, they should be admitted to establishments for general child care.

(ii) $B C G$. There is evidence that BCG may anticipate the conversion to positivity of the lepromin test in children and that with or without BCG there is a group of poor or slow responders in whom the lepromin reactivity cannot be achieved. Field studies are necessary to determine whether that anticipation is useful to individuals not yet exposed to $\boldsymbol{M}$. 
leprae and whether it may prevent leprosy in contacts and in those who are persistently lepromin negative. 'This study is difficult because of the relatively low incidence of leprosy and of the need of following up the studied group for some years.

At the same time, research should be continued to determine the relation between intensity of lepromin reaction and age, with oral and intradermal BCG, influence of larger doses, the bchaviour of individuals of other age-groups especially $0-6$ months and adults, the effect of BCG in children and adults previously exposed to $M$. leprae or not and persistently lepromin negative, and the eventual need of re-vaccination.

There is urgent need to continue research on the preventive value of BCG in leprosy and these studies are strongly recommended.

(iii) Chemoprophylaxis. Some rescarch has becn made on chemoprophylaxis but there is not yet a definate conclusion on its value as a preventive measure. Chemoprophylaxis trials are very important to ascertain whether it might be uscful or not to houschold contacts and what would be its duration and the best dosage.

As data confirming or refuting the effectiveness of either of both methods of protection (BCG and chemoprophylaxis) are as yet insufficient, no recommendations can be made. It is hoped that the trials now in progress may lead to a definite conclusion.

3. TRAining. Adequate carefully planned graded training should be given to all the different categories of personnel involved in a leprosy campaign, the length and content of this training being in accordance with the function they are to perform.

Clinical and didactic instruction should be given to medical students and it is recommended more time be allocated to leprosy in the curriculum.

Post-graduate courses for doctors coming to an endemic area, for general practitioners and health officers should be run at regular intervals, since all medical disciplines are likely to be consulted, often first, and their co-operation is of major importance.

Paramedical personncl: in many countries leprosy control rests with these workers and will do so for many years. Special consideration should be given to their selection and to their training which should be practical rather than academic, particularly with regard to complications which require to be referred to a doctor.

Selected people from this group may be given further training at a later stage to fit them for supervisory posts.

Other grades including nurses, midwives, social workers, in fact all those who may come into contact with leprosy in their routine duties should be able to recognise leprosy and take appropriate action.

4. HeAlth Education. Leprosy is a health problem and as such it should be dealt with in accordance with the principles that apply to other diseases. Health education is an instrument of the highest value in facilitating the application of control methods. It is sometimes best to link health 
education for leprosy with other health education campaigns, in order not to single out leprosy as a peculiar problem.

In all countries where leprosy is endemic, efforts undertaken to explain to the public the nature of the disease and the steps taken to control it should be continued and expanded. 'The cause, early signs and effect of treatment, should be explained, and the information disseminated by all means available. Authorities as well as the public should be reached and it should be included as part of the health programme in schools. It should stress that early treatment and care may prevent deformity and that deformity itself is correctable.

However, it is by personal contact that health education is best attained. Co-operation of the government officials, various influential bodies and persons, such as churches or unions, should be sought.

Organised community efforts to promote leprosy control and to help the patients should be stimulated through the leaders of the community. On the village level, health and social workers, school teachers and other authorities should assume leadership in this matter. Health workers should be made aware that their responsibility is actively to promote health in the community, not merely by distributing tablets and filling in reports. Information on leprosy should be included in the curriculum of teachers' training school.

'The co-operation of persons familiar with the local conditions should be sought.

With respect to education of the patients and contacts, it is essential that the patient and his family understand the nature of the illness and the reasons for the precautions involved. The risk of injury and the results of neglect must be explained to the patient and he must be alert for the possible development of deformity and report it. His whole training, be it in hospital or at home, must emphasise that, with regular treatment, his place in the community is not lost and he must be prepared to resume his responsibilities.

5. Social measures. Although noticeable progress has been accomplished in the last several years, erroneous concepts regarding the disease continue to impose harsh and unjustifiable penalities upon the leprosy patient and his family. The obligation of society to render assistance, education, medical care and social help are complementary in public health.

In addition to free medical care and drugs, various types of social assistance are directly related to control, and apply to the leprosy patients in general, viz:

(a) Assistance for travel to and from the clinics.

(b) Help for families in which the breadwinner is unable to work, in order to prevent misery and social disintegration.

(c) When advisable for medical or social reasons, removal of young children from the home and their placement elsewhere.

(d) Aid in preserving family ties when the patient is removed to an institution. 
(c) Job) placement for discharged pationts.

lepprosy patients should never be refused medical care or admission to health centres or general hospitals when suffering from another discase. If lepromatous and infectious, they could be hospitalized in a special ward. 'The same applies to women for delivery.

Mental patients affected with leprosy and who require hospitalization for either one of the discases should get care for both, regardless, of the type of institution they are in. Co-eperation of the leprologist and the psychiatrist is necessary.

Imprisonment should not be a bar to obtaining treatment.

Children with leprosy should never be denied the right to education. for lepromatous children, however, it may be necessary that special school facilities be provided.

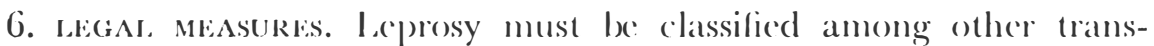
missible discases, and special legislation directed to the discase should be abolished. In the meantime, where extravagant legislation is not yet repealed, the application of the existing laws must be brought into line with present knowledge.

Reporting of the disease to the health department, however, is a necessity and should be required on the part of the physicians or other professional personnel in charge. The importance of professional secrecy in doctors and auxiliaries is stressed.

Indiscriminate compulsory segregation is an anachronism and has to be abolished. I)iscretionary authority could in certain circumstances be given to health officials to require isolation of lepromatous patients discharging bacilli in those instances in which sulfone therapy is neglected or ineffective.

The only desirable compulsory measure is the medical examination for transmissible discases.

On the international level, special attention should be paid to nomadic populations, especially when campaigns are unequally developed on two sides of a border.

7. Researcir. 'The control of leprosy is closely dependent on the present state of knowledge concerning the epidemiology of the discase. For example, a better understanding of the mechanism of transmission may bring about basic changes in our present methods of control.

I'here is, however, another type of research directly related to the procedures of control. 'This may be called research in the field of management and administration of public health.

The evaluation of the best methods for the integration of leprosy control in general public health activities is one example. Combination of a leprosy campaign with other health campaigns is advantageous, but not all are likely to yicld the same returns and to display the same efficiency. The possible psychological effect of one-shot, fast acting campaigns, such as a dramatically effective yaws' campaign, on the cooperation of the patients of the same community engaged in a treatment 
of long duration such as leprosy, should be studied.

'The problem of the poor attendance to tieatment and of the very high rate of drop-out should be studied on a large scale. There seems to be different patterns of drop-out; they should be identified, their catuse found, and remedies proposed.

The relationship between the methods employed for giving the drugs and the co-operation of the patients, should be stressed.

The methods for training of paramedical personnel require special consideration, in order to develop teaching methods to stimulate their interest, promote their initiative, and prepare them in a practical way for the task that faces them.

'The choice of the best strategy for the detection of the maximum number of cases with the resources available, as well as the organization of the out-patient treatment, including allocation of time, budget and personnel, location of the clinics, determination of areas of priority, and fixation of mobile teams' itineraries and schedules, could bencfit by methods developed in the field of operational research and system analysis.

I.eprosy control should take advantage of the collaboration of specialists from other disciplines not only epidemiologists, biostatisticians and health educators, but also psychologists, cultural anthropologists, economists, management scientists and rescarch analysts.

It is hoped that rescarches on these problems will be conducted during the next few years, eventually under the auspices of wHo, and results made available for the $9^{\text {th }}$ International Congress.

At present, the whole body of measures recommended against leprosy is mainly directed at the recognised patients. With the progress of knowledge in microbiology and epidemiology leading to a better understanding of the ccology of $M$. leprae and its transmission among populations, also with the progress in therapy and the possible development of immunising agents, it is hoped that a more rational and better control of leprosy will be achicved. 